\title{
PERCEPCÕ̃ES DISCENTES SOBRE AVALIAÇÃO DA APRENDIZAGEM EM UMA GESTÃO MUNICIPAL DEMOCRÁTICA
}

I Faculdade de Educação da Universidade Estadual de Campinas (FE/Unicamp), Campinas-SP, Brasil; crimacha@unicamp.br

Il Fundação Carlos Chagas (FCC): Universidade Cidade de São Paulo (Unicid), São Paulo-SP, Brasil; ange.martins@uol.com.br

III Secretaria Municipal de Educação de Santo André, Santo André-SP. Brasil; gilne.fernandez@yahoo.com.br

IV Secretaria Municipal de Educação de Santo André, Santo André-SP Brasil; acrassis4@yahoo.com.br

V Secretaria Municipal de Educação de Santo André, Santo André-SP

Brasil; dulciabatista@yahoo.com.br

\section{CRISTIANE MACHADO' ANGELA MARIA MARTINS" GILNE GARDESANI FERNANDEZ"' ADRIANA CRISTINA REIS DE ASSIS ${ }^{\prime V}$ \\ DULCILENE APARECIDA BATISTAV}

\section{RESUMO}

Este artigo tem o objetivo de analisar as percepções de alunos sobre avaliação da aprendizagem no âmbito da política educacional implementada na rede municipal de Santo André (SP). Apresenta um estudo qualitativo que elaborou uma triangulação analítica entre aspectos do contexto da política educacional do município pautada na perspectiva de gestão democrática, com base em documentos oficiais; discute a literatura da área dos estudos sobre avaliação de aprendizagem; e apresenta informações colhidas, por meio de grupos focais, junto aos alunos do $5^{\circ}$ ano do Ensino Fundamental I de duas escolas municipais. As entrevistas foram examinadas com base na análise de conteúdo. Os dados demonstram que os alunos percebem a avaliação de forma positiva, como um instrumento que estimula e colabora com avanços na aprendizagem em sala de aula, indicando possíveis reflexos dos princípios da gestão democrática instaurada na educação municipal.

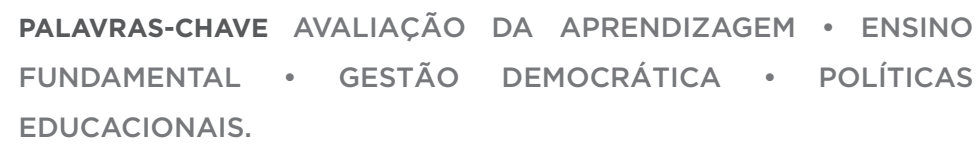




\section{PERCEPCIONES ESTUDIANTILES SOBRE \\ LA EVALUACIÓN DEL APRENDIZAJE EN UNA GESTIÓN MUNICIPAL DEMOCRÁTICA}

RESUMEN

Este artículo tiene el objetivo de analizar las percepciones de los alumnos sobre la evaluación del aprendizaje en el marco de la política educacional implementada en la red municipal de Santo André (SP). Presenta un estudio cualitativo que elaboró una triangulación analítica entre aspectos del contexto de la política educacional del municipio desde la perspectiva de la gestión democrática, en base a documentos oficiales; discute la literatura del área de los estudios sobre evaluación de aprendizaje; y presenta informaciones recogidas por medio de grupos focales junto a los alumnos del $5^{\circ}$ año de Educación Básica I de dos escuelas municipales. Las entrevistas se examinaron en base al análisis de contenido. Los datos demuestran que los alumnos perciben la evaluación de forma positiva, como un instrumento que estimula y colabora con avances en el aprendizaje en el aula, indicando posibles reflejos de los principios de la gestión democrática instaurada en la educación municipal.

PALABRAS CLAVE EVALUACIÓN DEL APRENDIZAJE • EDUCACIÓN BÁSICA • GESTIÓN DEMOCRÁTICA • POLÍTICAS EDUCACIONALES.

\section{STUDENT PERCEPTION OF LEARNING EVALUATION IN DEMOCRATIC MUNICIPAL MANAGEMENT}

ABSTRACT

This article aims to analyze student perception of learning evaluation regarding the educational policy implemented in the municipal school network of Santo André (SP). It is a qualitative study that used analytical triangulation to assess aspects of the educational policy of the municipality, grounded in a democratic management perspective, based on official documents. It discusses the literature in the field of learning evaluation, and presents information collected through focus groups with 5th grade students from two municipal schools. The interviews were analyzed using content analysis. The data show that students see the evaluation positively, as an instrument that promotes and supports advances in classroom learning, indicating possible reflections of democratic management principles implemented in municipal education.

KEYWORDS LEARNING EVALUATION • ELEMENTARY SCHOOL • DEMOCRATIC MANAGEMENT • EDUCATIONAL POLICIES. 


\section{INTRODUÇÃO}

O objetivo deste artigo é analisar as percepções de alunos do Ensino Fundamental I, de duas escolas municipais de Santo André (SP), sobre avaliação da aprendizagem à luz da literatura relativa ao tema e no contexto de implementação de uma política educacional municipal fundamentada nos princípios da gestão democrática desde 1989. As informações foram coletadas em dois grupos focais nas duas escolas pesquisadas, utilizando-se de um roteiro semiestruturado. Cada grupo focal teve a participação de dez alunos dos $5^{\text {os }}$ anos com idade entre 9 e 11 anos.

Trata-se de um estudo qualitativo, uma vez que tem a preocupação de interpretar a complexidade do comportamento humano com vistas a apreender significados atribuídos pelos sujeitos envolvidos no processo de investigação, suas atitudes e tendências de comportamento. Explica Stake (2011) que a pesquisa qualitativa é marcada por ricas descrições de ações pessoais e ambientes complexos e, assim, não existe uma única forma de pensamento, mas uma coleção de formas, pois é interpretativo e baseado nas experiências e situações analisadas, atribuindo-lhes significados. 
A investigação pautou-se na triangulação analítica, recurso que combina diferentes métodos de coleta e análise de dados utilizado para ampliar as interpretações do/s pesquisador/es a partir da adoção de diferentes percepções para esclarecer o significado das observações (STAKE, 2011).

$O$ pressuposto que embasa este estudo é o de que a realidade social é objetivada (os indivíduos e os grupos lançam mão de palavras, objetos, regras, símbolos e instituições transmitidos por gerações passadas), transformada e exteriorizada, criando, ao mesmo tempo, um campo de ação social; simultaneamente, essa realidade social é subjetivada e interiorizada (constituída de formas de sensibilidade, percepção, representação e conhecimento) (CORCUFF, 2001).

Conforme se discutiu em trabalho anterior (MARTINS, 2008), as percepções dos sujeitos são constituídas em processos interativos - permeados por motivações e interesses individuais - tendo em vista que, na perspectiva weberiana, toda ação é movida por uma conduta à qual o indivíduo associa um significado, tornando-se social apenas na medida em que o sentido de sua ação se relaciona às ações de diferentes atores, gerando situações interativas.

Há que se ressaltar, ainda, que considerar aspectos subjetivos não compromete a necessária credibilidade dos resultados. A garantia da confiabilidade na análise dos dados se dá por meio da triangulação, isto é, na recolha e análise de dados a partir de distintos ângulos, com o propósito de colocá-los em perspectiva. Nessa direção, lançamos mão da análise do contexto da política educacional de Santo André, com base em documentos oficiais; na literatura da área que discute resultados de estudos sobre avaliação de aprendizagem; e em informações colhidas junto aos alunos.

Optou-se por realizar dois grupos focais com alunos do Ensino Fundamental I da rede municipal de Santo André, tendo em vista que o procedimento permite conhecer as

[...] representações, percepções, crenças, hábitos, valores, restrições, preconceitos, linguagens e simbologias prevalentes no trato de uma questão por pessoas que partilham alguns traços em comum (GATTI, 2005, p. 11), 
possibilitando-nos compreender significados que seriam difíceis de se manifestar em outra técnica. Acrescente-se que, embora esses grupos não reproduzam ipsis litteris os cenários naturais nos quais ocorrem as interações cotidianas, eles permitem a emergência de mecanismos presentes nos processos interativos face a face e/ou institucionais.

A partir do registro das discussões dos grupos focais, realizou-se a análise de conteúdo das comunicações coletadas com base nos pressupostos de Bardin (1994). Trata-se de um conjunto de estratégias que permite analisar as comunicações por meio de uma organização sistemática e objetiva para desvelar os conteúdos das mensagens. Ao organizar essas comunicações em categorias, definidas por critérios de semelhança, procedeu-se a comparações e inferências sobre as características das falas. Os grupos foram organizados de forma a coletar a maior quantidade de dados acerca das percepções dos alunos sobre avaliação de aprendizagem, buscando favorecer a compreensão das mensagens emergentes nas falas e nas reflexões dos participantes. Para Franco (2012, p. 21, grifo da autora):

\section{O ponto de partida da Análise de Conteúdo é a mensa- gem, seja ela verbal (oral ou escrita), gestual, silenciosa, figurativa, documental ou diretamente provocada. Neces- sariamente, ela expressa um significado e um sentido.}

As entrevistas foram transcritas e procedeu-se inicialmente à leitura "flutuante" dos dados, pois, para Franco (2012, p. 54), a leitura "flutuante" é "a primeira atividade da pré-análise que consiste em estabelecer contato com os documentos a serem analisados", para, em seguida, elaborar a análise do conteúdo das entrevistas à luz da literatura do campo da avaliação da aprendizagem.

Este texto está organizado em quatro partes, além desta introdução. Inicialmente, é destacada a relação da avaliação com o cotidiano escolar, a seguir, engendram-se informações sobre o contexto da política educacional de Santo André com base na gestão democrática, posteriormente, as entrevistas são apresentadas e analisadas e, por fim, tecem-se as considerações finais de forma a concluir o artigo em tela. 


\section{AVALIAÇÃO NA ESCOLA}

Embora a avaliação tenha surgido com o próprio homem, uma vez que “o homem observa, o homem julga, isto é, avalia” (VIANNA, 1997, p. 6), é na escola moderna que ela adquire relevância pedagógica e notória popularidade, com profusa capilaridade social e política. Dias Sobrinho (2000, p. 17) explica que a avaliação sempre esteve ligada ao sentido de seleção e "antes mesmo da institucionalização das escolas já era praticada para fins de seleção social”.

A origem da ideia de avaliação como mecanismo de seleção e mensuração está na psicometria, pretensa ciência que surgiu no século XIX como área da psicologia especializada em medir, por meio de testes, as capacidades e as mudanças comportamentais nos indivíduos. Naquela oportunidade, de rejeição ao regime monárquico e levante dos princípios liberais, a avaliação foi um importante instrumento utilizado para detectar e valorizar os esforços individuais de forma científica. Na visão de Franco (1997, p. 17, grifos da autora):

Por detrás dessa prática, nos laboratórios e nos institutos de psicologia, instalavam-se os grandes marcos teóricos do individualismo/liberalismo (ao supor igualdade natural entre os seres humanos), do 'cientificismo' (ao supor experimentação, quantificação, neutralidade, objetividade) e da planificação (ao supor controle, manipulação e previsão, em que o que se colocava como útil era saber para prever).

O peso desse momento histórico foi tão forte e marcante que avaliação e medida são, culturalmente, tratadas como conceitos indissociáveis. Como afirma Dias Sobrinho (2000, p. 19), a ideia de medir "colou na avaliação e também parece pertencer à sua essência”; para Vianna (1997, p. 9), “medir, quantificação de um atributo, segundo determinadas regras, é visto como avaliar”. A herança produzida por esse contexto engendrou marcas profundas na escola, que por muito tempo se orientou, quase que exclusivamente, na avaliação quantitativa de seus alunos e na sua utilização como dispositivo de aprovação e reprovação, propiciando polêmicas e debates entre pesquisadores do tema sobre os usos da 
avaliação como mecanismo de classificação, punição, exclusão, seletividade, autoritarismo, controle (CHUEIRI, 2008), e instauração do medo como forma de ameaça, castigo e intimidação (LUCKESI, 1998).

A utilização da avaliação com esses princípios e objetivos provocou marcas indeléveis em muitos estudantes. Pesquisa desenvolvida por Alvez e Cabral (2015, p. 639) buscou conhecer situações marcantes vividas por professores na época em que frequentavam a escola. Para tanto, foi solicitado que 185 professores narrassem o episódio que mais os tivesse marcado no seu percurso de alunos, em textos de 300 a 600 palavras. Do total de narrativas produzidas, 40 textos se referiam a episódios relacionados às práticas avaliativas e, dentre estes, 31 apresentavam

[...] situações relacionadas com práticas de avaliação que
são sentidas e interpretadas como práticas de abuso de
poder. Apenas nove registam um sentido de emancipação,
de desenvolvimento pessoal e/ou académico. Os sujeitos
que sofrem a avaliação expressam sobretudo os senti-
mentos de humilhação (12), violência física e/ou psicoló-
gica (8), estigmatização (5), havendo ainda ocorrências
relacionadas com a arbitrariedade, deceção e discrimina-
cãa de género. (ALVEZ; CABRAL 2015, p. 640)

A investigação de Alvez e Cabral (2015) foi realizada nos anos de 2012 e 2013, com professores com idade entre 40 e 50 anos, o que nos leva a concluir que esses professores, ao narrarem histórias de suas experiências escolares, estavam se remetendo à escola das décadas de 1960 e 1970, no entanto, ainda hoje as situações relativas à avaliação na escola provocam desconfortos nos estudantes. É o que se verifica na pesquisa conduzida por Sasaki, Oliveira, Barreto e Rocha (2014) com o objetivo de conhecer, por meio de depoimento, as percepções de alunos da primeira etapa do ensino fundamental sobre a avaliação na escola. As informações obtidas revelaram os seguintes sentimentos entre os alunos:

No dia da avaliação fico bem nervosa (estudante do 5응 ano - 10 anos). No dia fico nervoso, com medo de não dar certo (estudante do 3ano - 8 anos). Me sinto meio triste 
[...] (estudante do 1 ano - 6 anos). Fico nervoso no dia de avaliação [...] quando termino, sinto um alívio [...]. Quando esqueço um assunto na hora da avaliação fico muito nervosa (estudante do 4ำ ano - 9 anos). O dia de avaliação é agoniante [...] no dia de avaliação fico suando [...] sofro quando faço avaliação (estudante do 4ำ ano - 9 anos). (SASAKI; OLIVEIRA; BARRETO; ROCHA, 2014, p. 82)

Apesar disso, a literatura da área é eloquente em apontar que a avaliação da aprendizagem, quando conduzida com base em concepções opostas às descritas anteriormente e colocada a serviço do entendimento e da melhoria do processo ensino-aprendizagem, pode ser um significativo elemento direcionador do trabalho pedagógico e iluminar as decisões docentes. Para Perrenoud (2000, p. 49), uma das competências que os docentes devem ter para ensinar é administrar a progressão das aprendizagens na perspectiva da abordagem formativa, pois esse processo é crucial para "fundamentar decisões de aprovação ou de orientação necessárias mais tarde”. Méndez (2002, p. 74) corrobora tais perspectivas ao sustentar que:

[...] a avaliação torna-se importante no momento da informação prática aos professores sobre a qualidade das aprendizagens que os alunos estão realizando. Ao mesmo tempo, oferece uma boa oportunidade para melhorar tanto o processo de aprendizagem quanto as ações futuras de ensino mediante a reflexão, a autocrítica e a autocorreção a partir da prática escolar.

Chueiri (2008), analisando a trajetória histórica dos significados e concepções de avaliação na escola, reconhece um movimento de reação aos modelos estritamente tecnicistas e quantitativos de avaliação e advoga tentativas de ruptura com tais modelos ao destacar concepções que enfatizam o processo pedagógico e valorizam a dimensão subjetiva dos alunos. Conclui a autora que, nesse sentido, a avaliação é concebida de forma plural, flexível, e preconiza a importância de considerar diferenças, uma vez que avaliar significa "qualificar" (CHUEIRI, 2008, p. 61). Essa concepção 
encontra eco nos princípios defendidos por Hoffmann (2008, p. 17) para a avaliação na escola quando a autora ressalta que "avaliar é agir com base na compreensão do outro, para se entender que ela nutre de forma vigorosa todo o trabalho educativo".

\section{O CONTEXTO DO ESTUDO}

A rede municipal de Santo André dispunha, no mês de fevereiro de 2016, de 37.875 alunos matriculados em seus 86 equipamentos educacionais, sendo 51 de educação infantil e ensino fundamental e 35 creches. Do total de matriculados, quase a metade era de alunos de Ensino Fundamental I (SANTO ANDRÉ, 2016).

O percurso da implementação da gestão democrática na educação municipal de Santo André teve início em 1989 com a eleição, pela primeira vez, do Partido dos Trabalhadores (PT) para o governo do município. Uma administração fundamentada, de acordo com Silva (2011, p. 27), na "construção de uma política pedagógica voltada para o direito e a cidadania, pautada em princípios progressistas". O PT administraria a cidade, ainda, por mais quatro gestões, de 1997 a 2000, 2001 a 2004, 2005 a 2008 e 2013 a 2016.

A gestão petista trouxe princípios democráticos organizando e propondo, por exemplo, a participação de toda a rede na discussão do Estatuto do Magistério, Lei Municipal n. 6833, promulgada em 15 de outubro de 1991.

É importante resgatar que, na primeira gestão do PT em
Santo André (de 1989 a 1992), o Departamento de Educa-
ção - que na época fazia parte da Secretaria de Educação,
Cultura e Esportes - elaborou junto aos professores da
rede o Estatuto do Magistério, uma vez que esta categoria
não contava com um estatuto específico. Na elaboração
desse Estatuto, fez parte das decisões garantir tempo de
trabalho na jornada do docente para participar das reu-
niões pedagógicas. (SILVA, 2011, p. 49)

A implementação do Estatuto viabilizou a formação dos professores e a organização coletiva do trabalho pedagógico 
com a ampliação da carga horária dos docentes, proporcionando a implantação das reuniões pedagógicas semanais organizadas como espaços coletivos de discussão. Era um momento em que a concepção construtivista era posta com a intenção de que as escolas construíssem seus trabalhos a partir das necessidades da comunidade e dos alunos, considerando também as individualidades.

Com o objetivo de (re)qualificar a formação docente que acontecia nas unidades escolares do município de Santo André, as reuniões pedagógicas apresentavam como foco a intenção de tornar-se um espaço que favorecesse a reflexão sobre a ação docente, a análise dos resultados e o planejamento dos novos rumos, visando ao desenvolvimento dos alunos. Nessa perspectiva, as reuniões pedagógicas assumiam um amplo papel formativo do professor, que qualificava a sua prática a partir do debate e da reflexão coletiva; dos gestores, que ao participarem desse processo eram levados a conhecer o percurso de desenvolvimento das crianças e do trabalho pedagógico, comprometendo-se com ele; dos alunos que iriam vivenciar um projeto educacional fundamentado.

A proposta de formação continuada de professores e gestores da Rede Municipal de Santo André preconizava a relevância da elaboração e discussão do Projeto Político-Pedagógico nas unidades, garantindo tempo e espaço para o debate das dificuldades nas relações de ensino e aprendizagem, dos êxitos na aprendizagem dos alunos e de proposição de novas ações. Em outros termos, o município considerou os professores e gestores como autores de sua formação, ao buscar "fazer diferença” na construção do currículo oferecido a todos os alunos da rede, com repercussões na elaboração do Projeto Político-Pedagógico e na avaliação da aprendizagem (SANTO ANDRÉ, 2014).

Ressalta-se que a cidade de Santo André faz parte do grupo das Cidades Educadoras, ${ }^{1}$ cujo processo começou nos anos de 1990, em um encontro realizado em Barcelona com um grupo de governantes municipais que tinham como objetivo comum garantir a melhoria da qualidade de vida dos seus habitantes. Um dos princípios pactuados entre as cidades
1 Disponivel em: <http://www. cidadeseducadorasbrasil.net.br/ Cidade-Educadora.aspx.>. Acesso em: 29 set. 2015 
foi o investimento permanente na educação e na formação continuada de seus professores. No Brasil, 14 cidades fazem parte do grupo de Cidades Educadoras, sendo sediado em Santo André o encontro que ocorreu em 3 e 4 de novembro de 2015, durante o qual o município deu continuidade ao debate e à implementação de ações buscando primar pela reflexão sobre a educação integral do aluno. Nessa perspectiva, o escopo normativo da rede municipal de educação de Santo André, no período em pauta, preconizava fundamentar seu trabalho investindo na formação continuada de professores, ancorada em princípios de construção coletiva de conhecimentos, com a participação, autonomia e corresponsabilidade de todos, possibilitando que os espaços oportunizados pela gestão pública se desdobrassem em ampliação da qualidade da educação, por meio da reflexão sobre experiências e práticas dos educandos (SANTO ANDRÉ, 2014).

De 1993 a 1996, com a escolha popular de outro partido para o governo municipal, o trabalho em desenvolvimento foi interrompido; entretanto, na eleição seguinte, o PT retornou ao governo municipal. A partir de 1997, houve um período de 12 anos seguidos de gestões petistas, ideologicamente comprometidas com a formação humana e com o direito de todos ao acesso à escola e ao conhecimento, sendo que já no início era preciso atender às necessidades locais, ampliando o atendimento e melhorando a qualidade, articulados com as demandas nacionais para a educação (SILVA, 2011, p. 27-28). Para tanto, o governo priorizou três diretrizes: democratização do acesso e permanência, qualidade social da educação e gestão democrática da educação, com o objetivo de direcionar o processo de planejamento da gestão escolar no sentido de romper com as relações autoritárias e proporcionar a participação de todos os sujeitos.

Uma ação importante foi a criação dos conselhos de escola. Esta ação tinha como objetivo garantir a participação de todos os segmentos da escola e estimular o convívio com a comunidade escolar, incluindo docentes, estudantes e comunidade local. Também previa o exercício da autonomia no desenvolvimento dessas práticas. (SILVA, 2011, p. 41) 
Até 2016, a gestão democrática da educação era uma diretriz presente em todos os níveis, etapas e modalidades educacionais e, juntamente com a demais diretrizes: democratização do acesso à educação, qualidade social de educação, valorização dos profissionais da educação e proteção integral à infância e à juventude, define a política educacional do município.

Nesta administração, o desafio da educação é o de promover a integração de políticas e ações de diferentes áreas, como forma de assegurar o direito a uma educação de qualidade e democrática. Esse desafio deve orientar todo o processo de planejamento, execução e avaliação das políticas públicas da cidade. (SANTO ANDRÉ, 2015, p. 6)

A gestão democrática era considerada, em Santo André, um princípio indissociável da qualidade social da educação, correspondendo à autonomia e participação.

O princípio da gestão democrática não deve ser entendido apenas como prática participativa e descentralização do poder, mas como aperfeiçoamento da democracia, como uma estratégia de superação do autoritarismo, do individualismo e das desigualdades sociais. (SANTO ANDRÉ, 2015, p. 29)

A escola era vista como um espaço para as indagações, reflexões, curiosidades e para o diálogo, com o entendimento de que o direito à educação supõe o acesso, mas também a permanência e o aprendizado; assim as reuniões pedagógicas são os espaços para as análises, escolhas, discussões, elaborações e tomadas de decisões sobre os procedimentos didáticos, e o planejamento das aulas deve orientar-se pelo projeto político-pedagógico e pelas práticas de avaliação e registros, sendo considerado, nesse contexto, importante para a qualificação do ensino e da aprendizagem.

Por conhecimento escolar, compreendia-se uma construção que considera as experiências sociais e não uma transferência de informações, por isso a participação é primordial, sendo os espaços democráticos indispensáveis para a qualidade dessa construção. Assim, 
[...] no âmbito das unidades escolares, os Conselhos de Escola devem participar efetivamente do processo de elaboração, decisão e avaliação do Projeto Político Pedagógico da unidade. (SANTO ANDRÉ, 2015, p. 30-31)

Desde a implantação dos primeiros anos do ensino fundamental na rede municipal de Santo André, a avaliação era discutida como um processo de análise-reflexão-ação, baseada no levantamento dos conhecimentos dos educandos e das suas necessidades, como sujeitos históricos e sociais. A avaliação

[...] deve se construir num processo contínuo de observação e registro do desenvolvimento dos alunos, considerando suas possibilidades e características pessoais, em cada momento do trabalho pedagógico. (SANTO ANDRÉ 1999, p. 16)

Para isso, o registro das ações e as observações sobre o desenvolvimento dos alunos e do grupo tinham fundamental importância "para o acompanhamento e avaliação do processo, a partir da reflexão sobre teoria e prática, nas reuniões pedagógicas e no Conselho de Escola" (SANTO ANDRÉ, 1998, p. 17).

A avaliação é uma das dimensões da política de qualidade da Secretaria de Educação, sendo

$[\ldots .$.$] entendida [\ldots]$ como processual e cumulativa, envolvendo tanto aspectos quantitativos como qualitativos. Deve constituir-se como referência para as discussões nas reuniões pedagógicas e replanejamento das ações. (SANTO ANDRÉ, 2015, p. 22)

Os documentos oficias assim definiam a avaliação dos processos de ensino e aprendizagem:

Entendemos a avaliação como algo inerente, contínuo e dinâmico ao longo de todo o processo de ensino e aprendizagem do professor e do aluno e não como algo à parte e com data marcada, visando medida, classificação, interpretação ou resultado, a partir da aplicação de provas e demais instrumentos de medição e julgamento dos saberes 
dos alunos, para verificação e atribuição de valor, em forma de notas ou conceitos. Assumindo o compromisso de ir além do senso comum, entendemos a avaliação como mediação, como diálogo, um processo sistemático e dinâmico de tomada de decisão envolvendo relações entre o ensino e a aprendizagem. (SANTO ANDRÉ, 2008, p. 9)

O exposto evidencia a adoção de uma perspectiva avaliativa calcada em concepções que se aproximam da abordagem formativa (PERRENOUD, 2000), que é aquela que se preocupa em levantar elementos para acompanhar a progressão das aprendizagens dos alunos e obter informações para tomar decisões visando a potencializar o processo ensino-aprendizagem. Há que se relevar, ainda, o contexto de implantação de uma gestão democrática baseada na autonomia e participação, na qual se insere essa perspectiva de avaliação na escola. Certamente, esses aspectos se refletem nas práticas escolares e, consequentemente, na percepção que os alunos têm dos dispositivos pedagógicos, como a avaliação.

\section{PERCEPÇÕES DISCENTES SOBRE AVALIAÇÃO DA APRENDIZAGEM}

As escolas estudadas foram denominadas Amarela e Azul para preservar suas identidades e a dos alunos participantes do grupo focal. Na Escola Amarela, participaram do grupo focal dez alunos do $5^{\circ}$ ano do Ensino Fundamental I de dois $5^{\text {os }}$ anos diferentes (B e C), sendo três alunos com 9 anos, seis alunos com 10 anos e um com 11 anos. A maior parte dos alunos estuda na Escola Amarela desde a pré-escola, apenas uma aluna entrou na escola no ano anterior. Na Escola Azul, participaram dez alunos do $5^{\circ}$ ano do Ensino Fundamental I de três $5^{\text {os }}$ anos diferentes (D, E e F), sendo nove alunos com 10 anos e um aluno com 11 anos. Essa turma contava com dois alunos que estavam na escola há dois anos, um aluno há três anos, um aluno há quatro anos, um aluno há cinco anos e cinco alunos há seis anos.

As perguntas elaboradas gravitaram em torno da tentativa de conhecer, por um lado, se os alunos eram submetidos 
a muitas provas, se eles as consideravam difíceis, se eles se preparavam para elas, como se sentiam nos dias de prova, por que achavam que eram avaliados pelo professor; por outro lado, buscou-se compreender se o professor deixava claro o que iria cair na prova, qual a pontuação da atividade, se dava retorno e discutia a correção da prova com eles, se auxiliava quando algum aluno errava.

As entrevistas, nas duas escolas, transcorreram de forma tranquila, leve e, até certo ponto, divertida. Mesmo nas perguntas consideradas embaraçosas pelas pesquisadoras, os alunos demonstraram segurança e calma ao respondê-las. Era perceptível que todos estavam à vontade para falar sobre o que era perguntado, tanto que, em alguns momentos, vários falavam ao mesmo tempo, necessitando de intervenção da mediadora para que cada um falasse somente depois que o colega terminasse sua frase para não prejudicar a gravação que seria posteriormente transcrita.

Foi nesse ambiente descontraído e efusivo que as perguntas sobre avaliação da aprendizagem foram iniciadas. Logo na primeira pergunta, procurou-se saber por que eles achavam que eram avaliados pelos professores. Na Escola Amarela, os alunos disseram que os professores dão provas com dois objetivos: um "é para saber como a gente está", indicando a existência de avaliações conhecidas como diagnósticas, que são aplicadas para obter informações sobre como se encontra o conhecimento dos alunos; e o outro é "no final, quando ela quer acabar com a lição desta matéria, aí ela passa uma prova", apontando para uma avaliação mais formativa, ou seja, aquela que é feita para saber o que foi aprendido do conteúdo trabalhado.

As avaliações diagnósticas e formativas são as que mais contribuem com o processo ensino-aprendizagem dos alunos. Para Luckesi (1998), a avaliação diagnóstica é um instrumento essencial para ajudar os alunos na compreensão do seu conhecimento e na construção da sua autonomia. Haydt (2000, p. 16-17) esclarece que:

A avaliação diagnóstica é aquela realizada no início de
um curso, período letivo ou unidade de ensino, com a in-
tenção de constatar se os alunos apresentam ou não o 
domínio dos pré-requisitos necessários, isto é, se possuem

os conhecimentos e habilidades imprescindíveis para as novas aprendizagens. É também utilizada para caracterizar eventuais problemas de aprendizagem e identificar suas possíveis causas, numa tentativa de saná-los.

A avaliação formativa, de acordo com Bloom, Hastings e Madaus (1983), objetiva oferecer elementos para que o professor e o aluno tenham informações sobre a aprendizagem e possam localizar os principais pontos de dificuldades para eventuais correções de rota no percurso da organização das atividades escolares. Nas palavras dos autores, a avaliação formativa tenta

[...] investigar os tipos de evidências mais úteis ao processo, procura o melhor método de relatar essas evidências, e encontrar formas de reduzir os efeitos negativos associados à avaliação (BLOOM; HASTINGS; MADAUS, 1983, p. 130),

o que a difere da avaliação somativa, realizada ao final de determinado percurso de ensino-aprendizagem para classificar os diferentes níveis de rendimento de um grupo ou turma de alunos.

Os alunos não consideram que têm muita prova na escola e nem que as avalições são difíceis. Segundo eles, prestando atenção à aula, fazendo as lições e estudando em casa, vão se sair bem e, de maneira geral, as professoras explicam a metodologia das provas, os conteúdos e os valores das atividades. Segundo dizem, gostam muito das provas: "adoro! Eu já tirei dez numa prova. 0 resto é tudo nove, oito", revelou em tom de conquista importante um dos alunos. Demonstram que estudam para as provas, se preparam: "a gente estuda", afirmam; um aluno destacou: "a gente faz até música com as coisas que eu tenho que lembrar". Explicam que alguns professores ensinam macetes para que eles se lembrem de conteúdos na hora da prova: "a professora deu uma frase que dá para decorar os nomes de todos os planetas na ordem".

Apesar disso, evidenciam preocupação com as provas:

Eu me sinto nervosa no começo, mas depois que acaba eu... eu fico tremendo, o coração pula, eu falo assim... Larissa tá atrás 
de mim e eu falo: amiga, não vou conseguir. Aí, tipo, eu fico com muito medo de tirar nota baixa.

Essas são as expressões que os alunos utilizam para demonstrar a tensão nos dias de avaliação. Quando perguntados mais incisivamente o porquê dos temores, percebe-se que a preocupação tem relação com o atendimento às expectativas dos pais. Revelam os alunos terem medo de tirar notas baixas e serem castigados e/ou punidos pelos pais: "a minha mãe me deixa de castigo, sem celular, sem tablet por um mês; de levar surra do meu pai; minha mãe não me bate, ela só me deixa sem celular, sem tablet por um mês"; "a minha mãe conversa comigo, não pode ir pra praia e ainda me deixa de castigo!"; "eles sentem 'desorgulho' por a gente”; "minha mãe não me faz nada, só me deixa de castigo; o castigo da minha mãe é ficar sentada lá, olhando para a TV, e olha que pode assistir TV"; "a minha vida é o meu celular, mas a minha mãe já vai logo pra minha vida, hehe”. Há quem relate ter sofrido punição séria por ter tirado nota baixa: "teve um dia em que a minha me deixou dez horas em pé".

O estudo de Sasaki, Oliveira, Barreto e Rocha (2014, p. 82) corrobora os achados desta pesquisa no sentido da preocupação dos alunos em relação ao que os pais vão pensar e/ou fazer caso eles tirem notas baixas. Segundo as autoras, os alunos relatam que, ao receberem os boletins, os pais brigam, se a nota for ruim, tiram direitos, se a nota for ruim, ou dão direitos, no caso de notas boas, e dizem "muito bem", se a nota for boa, ou "não gostei disso", se a nota for ruim.

Com base nas investigações de Luckesi (1998) que reiteram o uso da avaliação como instrumento de controle, classificação e exclusão, procurou-se identificar qual o sentido da avaliação no cotidiano escolar para os alunos; nessa direção, foi perguntado qual a razão das avaliações, na percepção deles. De modo geral, os alunos dizem que as provas os ajudam a aprender, pois são atividades individuais e, assim, "a professora sabe quem aprendeu o quê". Algumas afirmações evidenciam, também, a percepção de que a avaliação é um mecanismo à disposição da aprendizagem deles: "para a gente aprender melhor"; "para a gente poder saber na vida"; "para a gente poder aprender mais do que a gente já sabe"; "para ver se você 
tá bom mesmo". Uma resposta, ao afirmar que a professora "passa a prova pra ver se a gente aprendeu tudo e saber se a gente tá bem", foi bastante taxativa em apontar o uso da avaliação como mecanismo estritamente pedagógico. Dois depoimentos indicam o uso da avaliação como forma de controle da disciplina, das conversas entre os alunos na sala de aula: "para a gente não conversar porque a prova é individual"; "porque a prova é individual, que é pra você não conversar e pedir a resposta". Os alunos afirmam, ainda, que as professoras fazem a correção das provas na lousa, reforçando o uso pedagógico do conteúdo perguntado na prova: "a nossa professora, depois que a gente entrega, ela faz tudo na lousa".

A referência da prova escrita feita em sala como base da nota bimestral é um consenso entre os alunos, no entanto, dizem que algumas professoras tiram nota por mau comportamento, mas não explicam isso com muita clareza, apenas ressaltam que não são todas as professoras. Nesse momento, o grupo fica dividido e tem início um debate entre eles: uma parte dos alunos afirma que a professora "não tira nota"; outra parte diz que a professora deles "tira nota, sim". Para equacionar a discussão, foi perguntado se eles achavam que faziam muitas provas e qual deveria ser, para eles, a base da nota dada pelo professor. Respondem que não consideram que fazem muitas provas e, dependendo da matéria, até gostam de fazer. Para eles, a nota deve ser atribuída pelo "esforço", um aluno diz pelo "esforçamento", como se quisesse indicar que a nota deve ser atribuída pelo exercício do esforço do aluno. Acreditam, ainda, que os professores deveriam, sim, avaliar os alunos em relação ao comportamento e que o esforço em sala de aula deve ser valorizado e servir como referência para compor a nota bimestral.

Além das avaliações em sala de aula, os alunos declaram fazer outras avaliações, como a prova da OBA (Olimpíada Brasileira de Astronomia), para a qual eles estudam em sala e da qual gostam muito de participar. Relatam não conhecer a Prova Brasil ou o Ideb (Índice de Desenvolvimento da Educação Básica), talvez porque ainda não tenham participado de nenhuma aferição, a primeira aplicação da Prova Brasil acontece no final do segundo semestre do $5^{\circ}$ ano. 
Na Escola Azul, as respostas foram muito semelhantes às dos alunos da Escola Amarela. Quando perguntados sobre avaliação, os alunos logo citaram a Olimpíada Brasileira de Astronomia, afirmando que gostam de fazer a prova e têm uma apostila específica para estudar para ela desde o $3^{\circ}$ ano. Para eles, a prova da OBA é diferente da prova da professora, que seria: "para ver como a gente está e passar de ano"; já para a OBA, eles precisam estudar "o universo e os astros". Alguns alunos consideram que aprendem também ao realizar as provas e enquanto alguns acham a prova do professor mais fácil, outros acham a prova do OBA mais legal. Ao que parece, a preparação e a prova são mais empolgantes, tanto pela expectativa que eles nutrem esperando a data da prova, como também por fazer parte de uma competição entre vários alunos e escolas.

Assim como os alunos da Escola Amarela, não consideram que fazem muitas provas, ao contrário, dizem que podia ter mais provas ainda "de matemática, de preferência, e ciências, história, geografia”. Segundo eles, as professoras explicam as avaliações, dão dicas sobre quais conteúdos serão abordados nessas ocasiões, ajudam os alunos com maior dificuldade e retomam os conteúdos na devolutiva e atribuição da nota da prova.

Quando perguntados para que servem as provas que fazem em sala de aula, os alunos afirmam que servem para verificar "em parcelas" o que foi aprendido por cada aluno e para identificar dificuldades, "ver como a gente está"; "no começo do ano, a professora deu uma prova para ver como a gente tá, se não tinha esquecido"; "pra avaliar, ver como a gente está" e contribuir na melhoria da aprendizagem, revelando uma concepção diagnóstica da avaliação do professor, segundo Haydt (2000, p. 20):

\footnotetext{
Não é apenas no início do período letivo que se realiza a avaliação diagnóstica. No início de cada unidade de ensino, é recomendável que o professor verifique quais as informações que seus alunos já têm sobre o assunto, e que habilidades apresentam para dominar o conteúdo. Isso facilita o desenvolvimento da unidade e ajuda a garantir a eficácia do processo ensino - aprendizagem.
} 
Os alunos afirmam que, após as provas, as professoras corrigem coletivamente as questões: "Ela dá em outro dia, demora mais tempo";

[...] é, ela já explica, tipo, olha, essa criança está com um pouquinho de dificuldade. Ela já vai explicando, e no outro dia, que todas já deram as notas para todas as provas, ela entrega pra gente ver.

Alguns destacam que a professora corrige e dá parabéns e muito bom; dizem isso deixando transparecer que gostam desses reforços positivos. Segundo o que informam, compreendem bem o significado de cada um desses conceitos; "parabéns" é para quem acertou e errou um pouco menos e "muito bom" para quem errou um pouco mais. Quando alguém erra muito, a professora não fala nada, ela já avisa antes "que se ela não falar o nome é porque errou mais que o mais próximo de ganhar muito bem e parabéns". Ressaltam que, quando a professora percebe uma dificuldade pontual, usa o recurso da tarefa em casa para tentar atenuar e fortalecer a aprendizagem. Na fala de um aluno, "eu tinha dificuldade de fazer continha de divisão, aí a professora ficou passando para eu levar pra casa pra eu aprender mais".

As notas finais dos alunos são compostas pelas notas das provas feitas ao longo dos períodos e notas por comportamento em sala de aula. E, como sugestão para uma forma diferente de avaliar, eles indicam que a professora considere a redação e caligrafia dos alunos, além de reaplicar atividades para que eles possam recuperar o que erraram anteriormente.

Assim como os alunos da Escola Amarela, os alunos da Escola Azul não conhecem a Prova Brasil e o Ideb, no entanto, a maior parte deles se lembra de ter feito a Provinha Brasil e, segundo eles, o conteúdo da prova era o mesmo que havia sido ensinado/aprendido na escola.

\section{CONSIDERAÇÕES FINAIS}

Os dados evidenciam a recorrência de uma avaliação da aprendizagem mais voltada para a colaboração com o processo ensino-aprendizagem do que com a seleção, exclusão 
e/ou punição dos alunos, pois estes não acham que fazem muita avaliação e, quando fazem, gostam.

As falas dos alunos denotam que eles compreendem que a avaliação na escola, feita pelos professores em sala de aula, contribui para o crescimento e aprendizagem dos conteúdos estudados, embora em algumas poucas passagens dos depoimentos seja possível notar o uso da avaliação como um instrumento de controle da disciplina. Destacam, ainda, que as professoras fazem a correção das provas na lousa e dão retorno individual do que eles acertaram e do que erraram, demonstrando uma concepção formativa de avaliação, que é aquela que fornece aos alunos feedback de seus progressos (HADJI, 2001).

Ao que parece, a avaliação da aprendizagem evidenciada neste estudo é utilizada pelos professores e percebida pelos alunos como mecanismo de melhoria da "ação dos sujeitos”, nesse caso, da aprendizagem dos alunos, não correspondendo à perspectiva presente em alguns estudos da área que analisam usos da avaliação como instrumento para classificar, punir, excluir, controlar e intimidar (CHUEIRI, 2008; LUCKESI, 1998). Embora não seja possível estabelecer relação linear entre políticas educacionais em âmbito municipal com desdobramentos em unidades escolares que garantam a aprendizagem com sucesso de alunos, os dados do estudo indicam tendência de prováveis repercussões positivas na implementação de atividades encetadas pela Secretaria Municipal de Educação, no que se refere à concepção de uso da avaliação como instrumento para potencializar a aprendizagem dos alunos.

Ao que parece, a gestão democrática preconizada pela política educacional implantada, com algumas interrupções, desde 1989, engendrou as bases para uma relação ensino-aprendizagem pautada em princípios mais autônomos e participativos e estes, por sua vez, se refletiram na percepção que os alunos têm da avaliação da aprendizagem praticada em sala de aula.

Assim, é possível inferir que as ações e propostas governamentais partiam da concepção de que as relações estabelecidas no contexto escolar, assim como a organização 
administrativa e pedagógica, podem interferir significativamente no desenvolvimento e aprendizagem dos alunos, o que se coaduna com a afirmação de Libâneo (2007, p. 303):

[...] pesquisas mostram que, entre os fatores propiciadores de melhor qualidade das aprendizagens dos alunos, estão as características organizacionais, que representam cerca de $30 \%$ desses fatores, com destaque para a capacidade de liderança dos dirigentes, especialmente do diretor, as práticas de gestão participativa, o ambiente da escola, a criação de condições necessárias para o ensino e a aprendizagem, a cultura organizacional instituinte, o relacionamento entre os membros da escola, as oportunidades de reflexão conjunta e as trocas de experiências entre os professores.

Nessa direção, vale destacar que, ao que tudo indica, mesmo sem a intenção de generalizar, a instauração de práticas democráticas no âmbito da gestão municipal é o melhor caminho quando se almeja que a avaliação da aprendizagem seja um instrumento para forjar a constante compreensão e melhoria da qualidade do processo ensino-aprendizagem.

\section{REFERÊNCIAS}

ALVES, José Joaquim F. M.; CABRAL, Ilídia. Os demónios da avaliação: memórias de professores enquanto alunos. Estudos em Avaliação Educacional, São Paulo, v. 26, n. 63, p. 630-662, set./dez. 2015.

BARDIN, Laurence. Análise de conteúdo. Lisboa: Setenta, 1994.

BLOOM, Benjamin S.; HASTINGS, J. Thomas; MADAUS, George F. Manual de avaliação formativa e somativa do aprendizado escolar. São Paulo: Pioneira, 1983.

CHUEIRI, Mary Stela Ferreira. Concepções sobre a avaliação escolar. Estudos em Avaliação Educacional, São Paulo, v. 19, n. 39, p. 49-64, jan./abr. 2008.

CORCUFF, Philippe. As novas sociologias: construções da realidade social. Bauru: Edusc, 2001.

DIAS SOBRINHO, José. Avaliação da educação superior. Rio de Janeiro: Vozes, 2000.

FRANCO, Maria Laura P. B. Pressupostos epistemológicos da avaliação educacional. In: SOUSA, Clarilza P. (Org.). Avaliação do rendimento escolar. 6. ed. Campinas, SP: Papirus, 1997. 
FRANCO, Maria Laura P. B. Análise de Conteúdo. 5. ed. Brasília, DF: Liber Livros, 2012.

GATTI, Bernardete A. Grupo focal na pesquisa em ciências sociais e humanas. Brasília, DF: Liber livro, 2005.

HADJI, Charles. Avaliação desmistificada. Porto Alegre: Artmed, 2001.

HAYDT, Regina C. Avaliação do processo ensino-aprendizagem. São Paulo: Ática, 2000.

HOFFMANN, Jussara. Avaliar para promover: as setas do caminho. Porto Alegre: Mediação, 2008.

LIBÂNEO, José C. Organização e gestão escolar: teoria e prática. Goiânia: Alternativa, 2007.

LUCKESI, Cipriano Carlos. Avaliação da aprendizagem escolar. 7. ed. São Paulo: Cortez, 1998.

MARTINS, Ângela M. A constituição de trajetórias profissionais: possíveis contribuições ao debate sobre o trabalho docente. Revista Iberoamericana de Educación, Madrid, v. 46, n. 9, p. 1-8, sept. 2008.

MÉNDEZ, Juan Manuel Álvarez. Avaliar para conhecer, examinar para excluir. Porto Alegre: Artmed, 2002.

PERRENOUD, Philippe. Dez novas competências para ensinar. Porto Alegre: Artes Médicas Sul, 2000.

SANTO ANDRÉ. Secretaria Municipal de Educação e Formação Profissional. Revista Estação Gente-Educação Inclusiva: Plano 1998. Santo André, SP: SME, 1998.

SANTO ANDRÉ. Secretaria Municipal de Educação e Formação Profissional. Revista Estação Gente - Educação Inclusiva. Caderno de formação. v. 1. Santo André, SP: SME, 1999.

SANTO ANDRÉ. Secretaria Municipal de Educação e Formação Profissional. Ressignificação das práticas pedagógicas e transformações nos tempos e espaços escolares. Santo André, SP: SME, 2008.

SANTO ANDRÉ. Secretaria Municipal de Orçamento e Planejamento Participativo. Anuário de Santo André 2014. Ano Base 2013. Departamento de Indicadores Sociais e Econômicos/DISE. Santo André, SP: SMOPP, 2014. Disponível em: <http://www2.santoandre.sp.gov.br/imagens/docsportal/ Anu\%C3\%Alrio_de_Santo_Andr\%C3\%A9_2014.pdf>. Acesso em: 18 jan. 2016.

SANTO ANDRÉ. Secretaria Municipal de Educação e Formação Profissional. Revista a Rede em Roda: a formação desenvolvida na rede de ensino de Santo André. Santo André, SP: SME, 2015.

SANTO ANDRÉ. Secretaria de Educação. Mapa de movimento de alunos. Santo André: GAE, fevereiro 2016.

SASAKI, Karen; OLIVEIRA, Luana C. P.; BARRETO, Maribel O.; ROCHA, Nívea M. F. Percepções de estudantes do ensino fundamental sobre sua avaliação de aprendizagem. Psicologia Escolar e Educacional, São Paulo, v. 18, n. 1, p. 77-86, jan./abr. 2014. 
SILVA, Deise de Oliveira da. A construção do projeto político pedagógico numa perspectiva democrática: uma experiência na rede municipal de ensino em Santo André, SP. Jundiaí, SP: Editorial, 2011.

STAKE, Robert. Pesquisa qualitativa - estudando como as coisas funcionam. Porto Alegre: Penso, 2011.

VIANNA, Heraldo Marelim. Avaliação: considerações teóricas e posicionamentos. Estudos em Avaliação Educacional, São Paulo, n. 16, p. 5-35, jul./dez. 1997.

Recebido em: 10 JANEIRO 2018

Aprovado para publicação em: 19 MARÇO 2018 